\title{
Performance and Quality of Working Life
}

Hans Pruijt, Erasmus University Rotterdam

PO Box 1738, 3000 DR Rotterdam, the Netherlands

Tel + $31(0) 104082071$

pruijt@,fsw.eur.nl

Preprint.

Published in Journal of Organizational Change Management, 2000, Vol. 13, Nr. 4, 389-400

\section{Abstract}

An examination of the deep structure of the discourse on the organization of work shows that the most successful texts share a common structure: they construct an ideal model in which performance and quality go hand in hand. They provide explanations for the self-constructed gap between the model and reality, and recipes for change. This type of discourse has widespread appeal, but there are shortcomings attached to it: an inevitable neglect of the employment relation (and accordingly inadequate analysis of resistance to organizational change) and undue optimism about the quality of working life (thereby de-legitimizing efforts, such as in Scandinavian and Dutch working conditions legislation, to establish the quality of working life as a value in its own right). Critical and empirical evaluative alternative approaches seem unable to capture substantial mind share.

\section{Introduction}

For writers on the organization of work, the road to fame and fortune is paved with ideals. A large class of successful books on the organization of work seems to be based on the same basic formula: depict some form of organizational utopian model, and assert that this model is the road to top performance; claim that increasing compliance with the model implies improving the quality of working life; identify obstacles and develop solutions while keeping the basic assumption of congruence of performance and quality of working life intact as much as possible. Examples of management books that exhibit this pattern are (Peters and Waterman 1982; Womack, Jones et al. 1990; Hammer and Champy 1994). There are also more scholarly works that show the same characteristics (Kern and Schumann 1984; Piore and Sabel 1984; Zuboff 1988; Appelbaum and Batt 1994). This pattern is also evident in (at least one strand of) Sociotechnical Systems Design (Dankbaar 1997: 573).

While drawing on critical theory, this paper evaluates the ideal centered way of picturing the relation between performance and quality of working life.

\section{Models for top performance}

Part of the recipe for success is finding a catchy label for the ideal model that should ensure top performance together with a top quality of working life. Thus (Womack, Jones et al. 1990: 13) launched lean production: producing, in comparison with traditional mass 
production, a larger variety of products, with less than half the working effort, with less than half the investment in machines, tools and floor space, with less than half of the inventories, and with less defects. And Hammer and Champy (1994: 32) describe Business Process Reengineering as "the fundamental rethinking and radical redesign of business processes to achieve dramatic improvements in critical, contemporary measures of performance, such as cost, quality, service and speed." For 1980's management bestseller authors Peters and Waterman (1982), the ideal was simply Excellence.

For Kern and Schumann (1984: 19), the ideal is the organization based on New Production Concepts. Piore and Sabel's ideal is Flexible Specialization, while Appelbaum and Batt's (1994) is the High Performance Organization. Zuboff's ideal is the Informated Organization that is geared to exploit the capabilities of information technology to the fullest. Simple organizations with complex jobs is the ideal of modern Sociotechnical Systems Design (de Sitter, den Hertog et al. 1997).

\section{The claim that increasing compliance with the model implies improving the quality of working life}

In the ideal centered literature, the general claim is that increasing compliance with the model implies improving the quality of working life.

Peters and Waterman stress the importance of worker autonomy: "In the very same institutions in which culture is so dominant, the highest levels of autonomy occur. [..] people are encouraged to stick out, to innovate." (Peters and Waterman 1982: xxiii)

(Womack, Jones et al. 1990: 14) assure us that: "Most people - including so-called bluecollar workers - will find their jobs more challenging as lean production spreads." and that "Lean production calls for learning far more professional skills and applying these creatively in a team setting rather than in a rigid hierarchy." Womack, Jones et al. (1990: 199) assert that "Management stresses that problem-solving is the most important aspect of any job." They claim that automation will do away with routine tasks: "Thus by the end of the century we expect that lean-assembly plants will be populated almost entirely by highly skilled problem-solvers whose task will be to think continually of ways to make the system run more smoothly and productively" (Womack, Jones et al. 1990: 102).

And Hammer and Champy (1994: 53) claim that: "Instead of separating decision-making from real work, decision-making becomes part of the work. Workers themselves now do that portion of a job that, formerly, managers produced." They say that work becomes "more rewarding since people's jobs have a greater component of growth and learning" (Hammer and Champy 1994: 69). Amplifying this point, they tell us that "Companies that have reengineered don't want employees who can follow rules; they want people who will make up their own rules" (Hammer and Champy 1994: 70).

In both "Reengineering the Corporation" (Hammer and Champy 1994) and "The Machine that changed the World" (Womack, Jones et al. 1990), the congruence of performance and quality of working life is just an assumption because the authors do no supply any evidence. We find this assumption underlying not only management texts both also more scholarly work. Alvesson has already observed this phenomenon, when he analyzed a set of studies dealing with working life. In this set of studies, he found three underlying paradigms, of which the authors themselves seemed unaware: consensus (acceptance of present-day society), control (class struggle) and critique (total rejection of one-dimensional society) (Alvesson 1987). Consensus theorists believe that, as far as the organization of work is 
concerned, there is no fundamental conflict of interest between managers and workers. This implies that boosting performance and improving the quality of working life are two sides of the same coin. In the ideal-centered studies, this assumption is easily found. Kern and Schumann's new production concepts revolve around greater respect for skill and worker involvement: "The restrictive use of human labor discards an important potential for productivity. All-round tasks do not involve any dangers, only opportunities; qualifications and professional autonomy are forces of production, that need to be used more intensively." (Kern and Schumann 1984: 19)

And in Zuboffs informated organization, widespread and deep learning is essential: "an informated organization is structured to promote the possibility of useful learning among all members and thus presupposes relations of equality." (Zuboff 1988: 394)

In recent years, Sociotechnical Systems Design (especially in the Dutch tradition) also started to see performance and quality of working life as to sides of the same coin (Dankbaar 1997: 573).

\section{The gap between the model and reality}

The ideal centered literature tries to show that the ideal is attainable by presenting cases that conform to the model, or that at least show traits that conform to the model. At the same time, the ideal must not be too close to mainstream reality, otherwise the author's claim for attention would be invalid.

This gap between ideal and reality is constructed; it is a necessary corollary of the act of stating an ideal model. Nevertheless, the unfolding of the ideal-centered stories requires identification of obstacles and solutions. Meanwhile, the basic assumption of congruence of performance and quality of working life must remain intact as much as possible.

One way of preserving the basic assumption of congruence of performance and quality of working life is to define the one in terms of the other. This feat has been performed in the Integral Organizational Renewal approach. It has three main (re)design objectives: flexibility, controllability and quality of work (De Sitter quoted in Van Eijnatten 1993: 143). However, it defines quality of work in terms of "control capacity", i.e. "structural possibilities to cope effectively with variance" (Van Eijnatten 1993: 179). Thus, quality of work is an instrumental concept directed at adjusting the level of flexibility to business requirements. Theoretically, this means that an assembly line based factory could be a sound sociotechnical design, provided that there are no large fluctuations in its environment. Another way of developing an ideal-based discourse is by identifying enemies that resist the ideal. Likely candidates are (middle) managers who cling to their obsolete power. For example, BPR would be resisted by "middle managers, whose power and turf are likely to be diminished" (Hammer and Champy 1994: 223) and "barons running functional silo' s"(Hammer and Champy 1994: 107). And the chief bottleneck in Zuboff's road to the informated organization consists of managers who refuse to share their knowledge with workers or can't resist the temptation to use automatic data collection and electronic communication as control tools. (Zuboff 1988). Empirical testing of the manager-as-enemy theory is difficult, since we are essentially dealing with non-decisions. In a study of 150 change projects, however, there was some evidence of management obstruction. (Pruijt 1997) 
Ethnographic research on automation processes yielded some evidence as well. In one such study, a manager was quoted : "We have not given the operators the skills they need to exercise this kind of judgement because we don't trust them" (Zuboff 1988: 251). An engineer said: "many managers [..] tend to try and keep he operators in the dark as a form of job security." (Zuboff 1988: 252) By its nature, the ideal centered literature is (sometimes implicitly) prescriptive. In this respect, the ideal centered approach offers endless opportunities for theoretical expansion. It is always possible to point out that not enough attention is being paid to factors such as participation (too little or too much), management commitment, culture, communication, organizational learning, parallel learning, n-th-loop learning, the necessity of an integral approach, flows, processes, chaos, complexity and so forth. It possible to formulate an endless chain of new recipes for change, not unlike diets. Moreover, change programs mostly fail (Beer, Eisenstat et al. 1990). Even Hammer and Champy, who tend to make wild claims about BPR, estimate that 50-70 per cent of all BPR efforts fail (Hammer and Champy 1994: 200). Disappointment with ineffective recipes creates a demand for new, different recipes. Thus the proliferation of recipes may be an instance of the general behavior that people show when they try to keep a belief system alive in the face of lack of success (in this case, it is the belief in the assumption that performance and quality of working life are two sides of the same coin). Analogies can be drawn to astrology and compulsory gambling (Weizenbaum 1984).

\section{Advantages of the ideal centered approach}

An advantage of ideal centered discourse is its messianic appeal; although is may paint a gloomy picture of much of present organizational reality, it offers a hopeful perspective, something to strive for. Both production and consumption of this literature involves constructive thinking. It encourages the play of imagination.

Within the ideal centered approach, there is space for advocating a wide range of solutions, both Tayloristic and non-Tayloristic ones (Pruijt 1998). Moreover, an ideal model can be a convenient conceptual took for researchers who are trying to make sense of the empirical reality in organizations.

\section{Critical theory and the relationship between performance and quality of working life}

In the ideal centered approach, the relation between performance and quality of working life is generally positive. There is, however, a literature in which this relationship generally is a negative one. In Critical Theory especially, the clash between efficiency and humanization is a central point. This clash is apparent in, for example, an article entitled "Some implications of modern technology" that Herbert Marcuse published in 1942. In this article, the Third Reich serves as a powerful example to show how extreme the clash can be. Marcuse sees modern industrialized society as a system, characterized by "standardized control, production and consumption". In this system, autonomous, critical reason has lost its meaning and has been transformed into adjustment and "efficient compliance with the pre-given continuum of means and ends" (Marcuse 1941: 419). At the same time, he sees this system as highly efficient. (Marcuse 1941: 422) 
But also in a management-oriented text like Mintzberg (1983: 180), one finds the following statement: "As long as society demands cheap, mass-produced goods and services - a great many jobs will remain pretty much as they are now".

Already in Max Weber's work the clash between efficiency and humanization can be found. For Weber (in Gerth and Mills 1977: 214), the most efficient form of organization is the bureaucratic organization: "The decisive reason for the advance of bureaucratic organization has always been its purely technical superiority over any other form of organization. The fully developed bureaucratic mechanism compares with other organizations exactly as does the machine with the non-mechanical modes of production." And perfection of the bureaucracy is the opposite of humanization: "[Bureaucracy's] specific nature, which is welcomed by capitalism, develops the more perfectly the more bureaucracy is 'dehumanized', the more completely it succeeds in eliminating from official business love, hatred, and all purely personal, irrational, and emotional elements which escape calculation" (in Gerth and Mills 1977: 216).

Authors who are strictly working inside the critique paradigm tend to dismiss any change in the organization of work as solely in the interest of capital and its managerial agents.

For example, Doorewaard (1989: 52) sees job redesign as a "control strategy". Kelly (1982) asserts that job redesign is primarily adaptation of the organization of work to turbulence in product markets while intensifying work. Braverman (1974: 39) views work reform as "a style of management rather than a genuine change in the position of the worker", while Ramsay (1985: 59) analyses the phenomenon as concessions that managers make in times when their legitimacy is threatened.

The problem is not that these assessments might be completely incorrect. The problem is that the theoretical framework these authors use does not allow for cases in which job redesign leads to a genuinely improved quality of working life. The pure critique paradigm leads to paralysis of action.

\section{Disadvantage of the ideal centered approach: undue optimism about the congruence of performance and quality of working life}

Is the inadequacy of the pure critique paradigm a reason to accept the ideal based approach as unproblematic? We can explore this question by juxtaposing consensus-oriented and critical viewpoints.

The common line of argument in the ideal centered discourse is to point to challenges that organizations face (such as the need to come up with more quality, flexibility, speed and innovation) and to show that these challenges can be met by implementing strategies that lead to increased performance and improved quality of working life simultaneously.

However, this line of argument can be subjected to the critique that generally there also exist alternative strategies to tackle these challenges, and that these alternative strategies involve less humanization.

Ideal centered discourse: In order to thrive, companies must innovate. Therefore employees will get space to unleash their creativity.

Critique: Yes, but many companies satisfy their innovation needs by buying up small, innovative companies, or concentrating innovation in a separate department or in a "skunk works". In this way, the jobs of the main work force can remain routine. 
Ideal centered discourse: Nowadays, companies need to respond more quickly to varying customer demands. Teams are the solution.

Critique: Many companies will be able to retain large Tayloristic production units for the predictable parts of production, while having semi-autonomous teams operating in parallel with this to provide flexible quick response capability.

Ideal centered discourse: In a centralized organization, an increasingly turbulent environment leads to an increased information load. The solution is: empowering workers to make decisions themselves.

Critique: Yes, but there is also the alternative strategy of using information technology for maintaining the old level of central control.

Ideal centered discourse: Continuous improvement is necessary. In order to be competitive, organizations have to become learning organizations, which involves employee empowerment.

Critique: Yes, but there is also the model of the learning bureaucracy, in which workers' brains are tapped without devolvement of power.

Ideal centered discourse: customized production is taking the place of mass production. Higher skill requirements are the result.

Critique: Yes, but how about mass customization? Modular construction allows customization based on unskilled work.

Ideal centered discourse: High performance organizations are high trust organizations (Fukuyama 1995).

Critique: Yes, but high trust organization is not compatible with downsizing. And that is what shareholders seem to like (Gordon 1996).

Such yes, but objections suggest that there are risks that quality of working life will be suboptimized when it does not receive attention as a value in itself. We have to bear in mind that in many situations there are not only benefits, but also costs associated with improving the quality of working life. The cause is the old Babbage principle: division of labor makes it possible to hire cheaper workers, in other words: nicer work, higher pay.

The picture becomes more complicated when we realize that the quality of working life, and especially its component part autonomy, is multidimensional. Improvement of one aspect of the quality of working life can be linked to a deterioration of another aspect. The practical value of an analysis that takes this into account, is that it can offer an understanding of employee resistance to change, which in ideal centered discourse might be pictured as irrational.

Generally, undue optimism is not a serious problem, sometimes it is more to the contrary. Without undue optimism, human development would grind to a standstill. However, in this case it de-legitimizes efforts to promote quality of working life as a value in its own right. After all, the quality of working life is taken care of automatically by focussing on optimizing performance. 
In ideal centered discourse, attempts to avoid naï veté about the congruence of performance and quality of working life are a source of internal stress. Frequently, ideal-centered authors acknowledge limits to the applicability of the central assumption of congruence of performance and quality of working life. Often this happens in passing, in just a few lines. For example, a famous book on BPR concedes that IT enabled process innovation supports not only empowerment but also control and states "We are not enthusiastic about controloriented culture (we wouldn't want to work in such environments), but they are possible and sometimes necessary." (Davenport 1993: 96)

And Zuboff's ideal of the informated organization rests on learning, on acquiring the intellective skills necessary for exploring the data interface. However, she points out that learning is not always as important; the urgency of learning is dependent on the level of uncertainty. This uncertainty varies with market and other conditions. (Zuboff 1988: 305)

In a more extensively argued way, Kern and Schumann exclude entire industries, such as food processing, from their new production concepts.

The strategy of delimiting the applicability of the central assumption provides an intellectual cordon sanitaire behind which the ideal-centered story can unfold undisturbed.

However, there are problems with this segmentation approach. What should be the unit of analysis: industries, types of products, individuals jobs, departments or hierarchical levels (Alvesson 1987)? Plus, there may be important ideal-undermining trends that do not stop at sector boundaries. For example, McDonalization (emphasis on efficiency, quantification and calculation, predictability and control through the use of technology) permeates segments far remote from mass production such as science and medicine (Ritzer 1993). Even if one is prepared to believe that performance and quality of working life can be two sides of the seem coin, it seems impossible to find a systematic rule as to when it applies and when not.

\section{Disadvantage of the ideal centered approach: the employment relationship is a blind spot}

When explaining why a given organization deviates from the ideal model, authors can not draw on factors that both the organization under study and the ideal model have in common. Normally both the organization studied and the ideal model rely on wage labor. This means that the influence of the employment relationship as such - i.e. not the contingent way in which this relationship may be shaped - will remain in the dark.

A critical look at the foundations of employment reveals that no matter how modern an employment relation is, it remains essentially antagonistic. The following three characteristics are always there:

1) Subordination. The single most defining characteristic of the employment relation is subordination of the employee to the employer (within limits defined implicitly and explicitly by the employment contract) (cf. March and Simon 1990).

2) Asymmetry. Employers and employees have equivalent market positions only on paper. In practice, control over the means of production is a decisive difference. The employment relationship is asymmetrical (Mok 1994: 200); generally the employee is more dependent on the employer than the employer is on a particular employee.

3) Employees are instrumental. Employees (i.e. "those that are being used") are instrumental in the accumulation of capital, which is, as Marx (1967: Vol. 1, Ch. 10) put it: "dead labor, which, vampire-like, lives only by sucking living labor, and lives the more, the 
more labor it sucks." This means that a worker, by putting much effort into his job, might help to generate profits that enable the company to make him redundant through automation or by relocating production to another country. Hyman (1984: 185) notes: "management's role as servants of accumulation means that there is a constant drive to reduce labor costs, to intensify the pressure of work, to render existing workers ' redundant' ."

These three immanent characteristics of the employment relationship lead to discontent often latent - on the part of the employees, that at certain times in history becomes unrest. There are many factors that can explain why this unrest rarely leads to radical action:

- While there is a conflict of interest between employee and employer regarding the distribution of revenues, employer and employee also have a common interest in maintaining continuity of the production process itself (Kelly 1982: 53). Conflict is necessarily mixed with co-operation.

- Employees are largely dependent on the employment relation.

- Institutionalization of class conflict in the system of industrial relations.

- Regulations, for example on the length of the working day and social security, improve the position of the employees.

- The Fordist triangle of mass production, high wages and affordable products.

- To many, alternative economic systems are not attractive.

- Individual escape from the employment relation into self-employment is often possible (although hiring the first employee means re-entry into the employment relation from the other side).

- A self-protecting power system avoids exercise of power in such a way, that classes confront one another as identifiable groups (Habermas 1968: 53). Habermas asserts that class conflict becomes latent, and that the conflict zone moves to other areas of society.

The general result, in the view of Ter Hoeven (1969: 34), is that "protest behavior" can surface in "turnover, absenteeism, reduction of performance, withdrawal of efficiency, manipulation of wage standards, verbal expressions and other forms of striking without quitting". He emphasized that in many cases, this does not involve class consciousness, but that protest behavior flows forth from "experienced but not recognized" conditions. The implication is a "constant struggle around the workers' margin of freedom". Therefore, unease related to the employment relation is not unilaterally characteristic of workers.

It is also a cause of stress for employers. As a joke goes: "In the New Year, I wish that you will have lots of employees in your business", said the businessman to his competitor.

The unease that emanates from the employment relation can take many shapes. Edwards (1990: 136) noted: "People develop policies to handle contradictions - or, to be more exact, to handle the consequences of contradictions, for people respond to felt pressures and not to the abstract nature of the mode of production." Conflict, tension or "structured antagonism" can be latent or dormant. Much has been laid down in rules and regulations, the costs of open conflict are high, a certain level of consent is needed for successful operation for the organization, schools to some extent prepare for the role of compliant worker (Edwards 1990).

Attempts by managers to jack up organizational performance can threaten the ways in which, in the words of Watson (1987: 223) "people adjust to the variety of ways in which they are made use of in the employment situation". To give an example: when a re-designed job requires constant attention, possibilities for daydreaming and conversation become less. Shop-floor culture is be an area where some self-expression takes place. According to Willis (1979: 188-189) "working class culture of work is not simply a foam padding, a rubber layer between humans and unpleasantness. It is an appropriation in its own right, an 
exercise of skill, a motion, an activity applied towards an end". Elements of shop-floor culture are a "half-mythical primitive confrontation with the task" (Willis 1979: 190) and a sense of competence involving the superiority of practice over theory. The social group is the basis. Apart from sexist attitudes, jokes are important (Willis and Corrigan 1983: 96).

A small gain in work interest as a result of job redesign might not compensate for the associated loss of self-expression through shop floor culture.

De-bureaucratization paradoxically can mean a loss of autonomy at the bottom of the organization. Following Crozier, Giddens (1981: 311) concluded that "it is plausible to argue that the more tightly knit and inflexible the formal relations of authority in an organization, the more they can be circumvented and manipulated by those in subordinate positions to their own advantage".

In order to perform any job effectively, an employee must do at least a little more than just follow the rules (cf. Edwards 1990: 140-141). If employees are, at the outset of job redesign, unwilling to put at least some creativity into their work, we can read this as resistance to the employment relation in general. Gorz (1980: 45) describes this kind of resistance as "active passivity".

Insofar as the change project involves participation, employees may fear that management appropriates their knowledge, thereby weakening the position of the employees; increased flexibility can threaten job security. Because the employment relationship is a blind spot, the ideal centered approach is unable to provide an adequate analysis of resistance to change.

\section{Conclusions and discussion}

The discourse on the relation between performance and quality of working life has one outstanding, dominant feature: a proliferation of ideal-centered texts. This literature has a wide appeal, directly and through the media, and it informs policy. Shortcomings are a neglect of the employment relation (and accordingly inadequate analysis of resistance to organizational change) and undue optimism about the quality of working life (thereby delegitimizing efforts, such as in Scandinavian and Dutch working conditions legislation, to establish the quality of working life as a value in its own right). Alongside, a critical literature exists which pictures the relation between performance and quality of working life as negative. Especially the pure variety of this critical approach is of little practical consequence because it does not offer the possibility of evaluating change; There is only one shade of black. However, there is a third stream of literature that tries to evaluate organizational changes that were made according to ideal-centered recipes or that seem to fit into patterns as sketched in ideal centered discourse (Child and Loveridge 1990; Huys, Sels et al. 1995; Pruijt 1997). However, this type of studies tend to lack the appeal that ideal centered discourse has. Therefore one can expect a continued large scale hopping from one ideal model to the next.

\section{References}

Alvesson, M. (1987). Organization Theory and Technocratic Consciousness: Rationality, Ideology, and Quality of Work . Berlin, De Gruyter.

Appelbaum, E. and R. Batt (1994). The New American Workplace: Transforming Work Systems in the United States. Ithaca NY, ILR Press.

Beer, M., R. A. Eisenstat, et al. (1990). "Why Change Programs Don't Produce Change." Harvard Business Review(november/december): 158. 
Braverman, H. (1974). Labor and Monopoly Capital: The Degradation of Work in the Twentieth Century. New York, Monthly Review Press.

Child, J. and R. Loveridge (1990). Information Technology in European Services: Towards a Microelectronic Future. Oxford, Basil Blackwell.

Dankbaar, B. (1997). "Lean Production: Denial, Conformation or Extension of Sociotechnical Systems Design?" Human Relations 50(5): 567-583.

Davenport, T. H. (1993). Process innovation : reengineering work through information technology. Boston, Massachusetts, Harvard Business School Press.

de Sitter, U., F. den Hertog, et al. (1997). "From complex organizations with simple jobs to simple organizations with complex jobs." Human Relations 50(5): 497-535.

Doorewaard, H. (1989). De Vanzelfsprekende Macht van het Management: Een verkennend onderzoek naar hegemoniale aspecten van de macht van het management bij automatisering . Assen, Van Gorcum.

Edwards, P. K. (1990). Understanding conflict in the labour process: the logic and autonomy of struggle . in: D. Knights and H. Willmott (eds) Labour Process Theory. Houndmills, Macmillan: 125-152.

Fukuyama, F. (1995). Trust : the social virtues and the creation of prosperity. New York, Free Press.

Gerth, H. H. and C. Wright Mills (1977). From Max Weber: Essays in Sociology. London, Routledge and Kegan Paul.

Giddens, A. (1981). The Class Structure of the Advanced Societies 2nd edition . London, Hutchinson.

Gordon, D. M. (1996). Fat and Mean. The corporate squeeze of working Americans and the myth of managerial "Downsizing". New York.

Gorz, A. (1982). Farewell to the working class : an essay on post-industrial socialism, London, Pluto

Habermas, J. (1968), Technik und Wissenschaft als "Ideologie". Frankfurt am Main, Suhrkamp

Hammer, M. and J. Champy (1994). Reengineering the Corporation. A Manifesto for Business Revolution. New York, HarperCollins.

Huys, R., L. Sels, et al. (1995). De Uitgestelde Transformatie: Technische en sociaalorganisatorische herstructureringen in de chemische, de automobiel en de machinebouwindustrie. Brussel, Federale Diensten voor wetenschappelijke, technische en culturele aangelegenheden .

Hyman, R. (1984). Strikes. London, Fontana. 3rd edition,

Kelly, J. E. (1982). Scientific Management, Job Redesign and Work Performance. London, Academic Press.

Kern, H. and M. Schumann (1984). Das Ende der Arbeitsteilung? Rationalisierung in der industriellen Produktion. München, Beck.

March, J. G. and H. A. Simon (1970). Motivational constraints: the decision to participate. in: V. H. Vroom and E. L. Dec (eds) Management and motivation.. Harmondsworth, Penguin: 107-124.

Marcuse, H. (1941). Some social implications of modern technology. Zeitschrift für Sozialforschung/Studies in Philosophy and Social Science. München, Deutscher Taschenbuch Verlag. IX: 414-439.

Mintzberg, H. (1983). Structure in Fives: Designing Effective Organizations. Englewood Cliffs, Prentice Hall.

Marx, K. (1967). Capital Vol I. New York, International Publishers 1887.

Mok, A. L. (1994). Arbeid, Bedrijf en Maatschappij. In het zweet uws aanschijns, , Stenfert Kroese. (tweede editie) 
Peters, T. and R. Waterman (1982). In Search of Excellence. New York, Harper and Row.

Piore, M. and C. Sabel (1984). The Second Industrial Divide, Possibilities for Prosperity. New York, Basic Books.

Pruijt, H. (1997). Job Design and Technology. Taylorism vs. Anti-Taylorism. London

New York, Routledge.

Pruijt, H. (1998). "Multiple Personalities: the Case of Business Process Reengineering." Journal of Organizational Change Management 11(3): 260-268.

Ramsay, H. (1985). What is participation for? A critical evaluation of 'labour process' analysis of job reform. in: D. Knights, H. Willmott and D. Collinson (eds) Job Redesign, Critical Perspectives on the Labour Process. Aldershot, Gower: 107-141.

Ritzer, G. (1993). The McDonaldization of Society: An Investigation into the Changing Character of Contemporary Social Life. Thousand Oaks CA, Pine Forge Press.

Ter Hoeven, P. J. A. (1969). Arbeiders tussen Welvaart en Onvrede. Alphen aan den Rijn, Samsom.

Van Eijnatten, F. (1993). The Paradigm that Changed to Work Place. Stockholm/Assen, Swedish Center for Working Life/Van Gorcum.

Watson, T. J. (1987). Sociology, Work and Industry 2nd edition. London, Routledge.

Weizenbaum, J. (1984). Computer Power and Human Reason: From Judgement to Calculation. Harmondsworth, Penguin.

Willis, P. (1979). Shop floor culture, masculinity and the wage form. in: J. Clarke, C. Critcher and R. Johnson (eds) Working-class Culture. London, Hutchinson.

Womack, J., D. T. Jones, et al. (1990). The Machine that Changed the World: Based on the Massachusetts Institute of Technology $\$ 5$ million 5-year study on the future of the automobile. New York, Rawson.

Zuboff, S. (1988). In the Age of the Smart Machine. The Future of Work and Power. New York, Basic Books. 